\title{
Excision of the Trapezium
}

\author{
Krishna Mohan Iyer* \\ Orthopaedic Surgeon, India
}

Submission: December 19, 2016; Published: January 23, 2017

*Corresponding author: K Mohan Iyer, K Mohan lyer, Senior Consultant, Orthopaedic Surgeon, Flat No: 120/H-2K, First Floor, Kailash Apartments, 8th Main Road, Malleswaram, Bangalore, 560003, Karnataka State, India, Tel: +919632683264; Email: kmiyer28@hotmail.com

\section{Original Work}

a) The Results of Excision of the Trapezium- K Mohan Iyer (Oct.1981) The Hand, Vol. 13,No. 3: 246-250.

b) Arthrography of the Metacarpo-Scaphoid Joint following Excision of the Trapezium- K Mohan Iyer \& GH Whitehouse (Oct.1981) The Hand, Vol.13,No. 3: 251-256 [1-39].

\section{The Trapezium Surfaces}

a. Palmar Surface-Groove and a Tubercle.

b. $\quad$ Dorsal Surface-Related to Radial Artery.

c. Lateral Surface-Lateral collateral ligament of the wrist joint \& capsular ligament of the carpometacarpal joint.

d. Medial Surface-Facet for the Trapezoid.

e. $\quad$ Proximal Surface-Facet for the Scaphoid.

f. Distal Surface-Saddle shaped for the base of the first metacarpal.

\section{Normal Wrist Joint Compartments}

a.Radiocarpal Joint.

bInferior Radioulnar Joint.

c.Midcarpal Joint.

d.Isolated Carpometacarpal Joint the Thumb (Figure1)

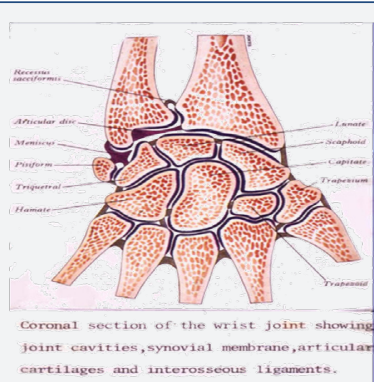

Figure 1: Coronal section of the wrist joint showing joint cavities, synovial membrane, articular cartilages and interosseous ligaments.

\section{Intercarpal Joints}

a. Joints between bones of the proximal row.

b. Joints between bones of the distal row.

c. Midcarpal Joint

i. Between these two rows of bones.

ii. S shaped cavity lined by synovial membrane.

iii. Has 2 projections proximally and 3 projections distally. Pathology

\section{Stage I:}
a. Pain
b. Synovitis
c. Local Swelling
d. Effusion into the joint (Figure 2)

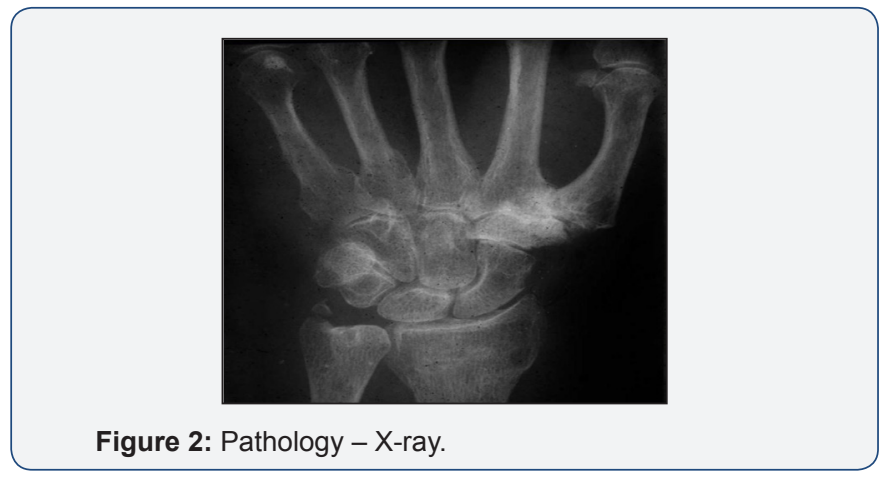

Stage II:
a. Severe pain
b. Joint space narrowing
c. Medial osteophyte (Figures 3 \& 4). 

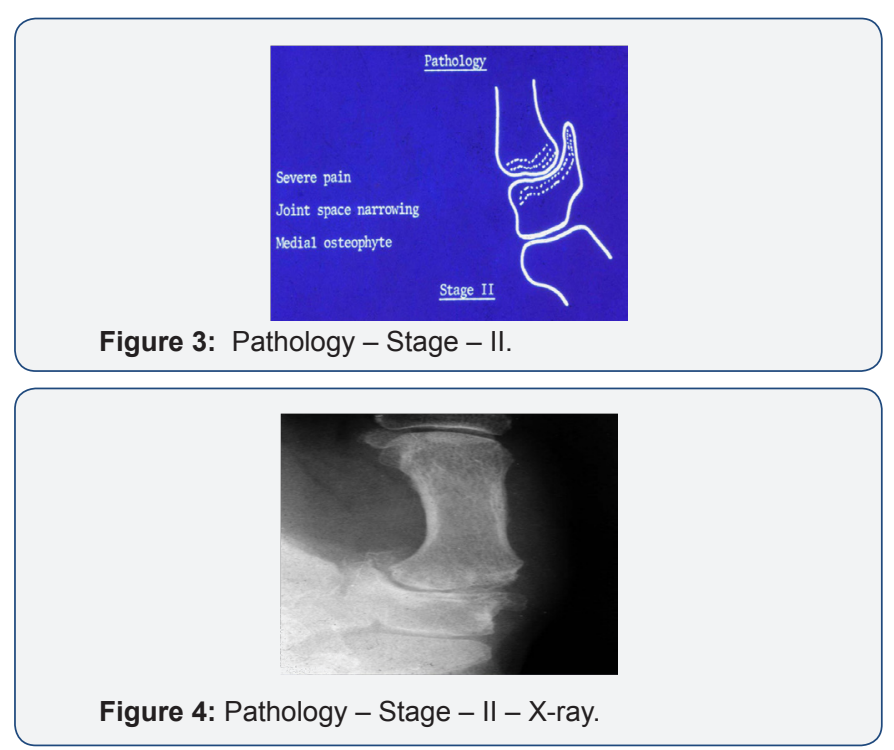

\section{Stage III:}

a. Severe pain

b. Marked decrease of joint space Subluxation of the metacarpal (Figure 5).

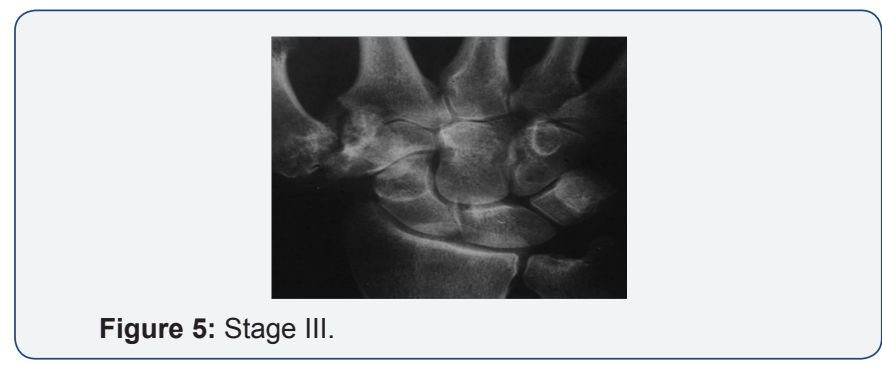

\section{Stage IV:}

a. Subluxated metacarpal fixed by fibrosis \& contracture

b. Marked hyperextension deformity of the MCP joint Flexion deformity of the IP joint

c. Pain minimal or nil Fixed adducted thumb (Figure 6).

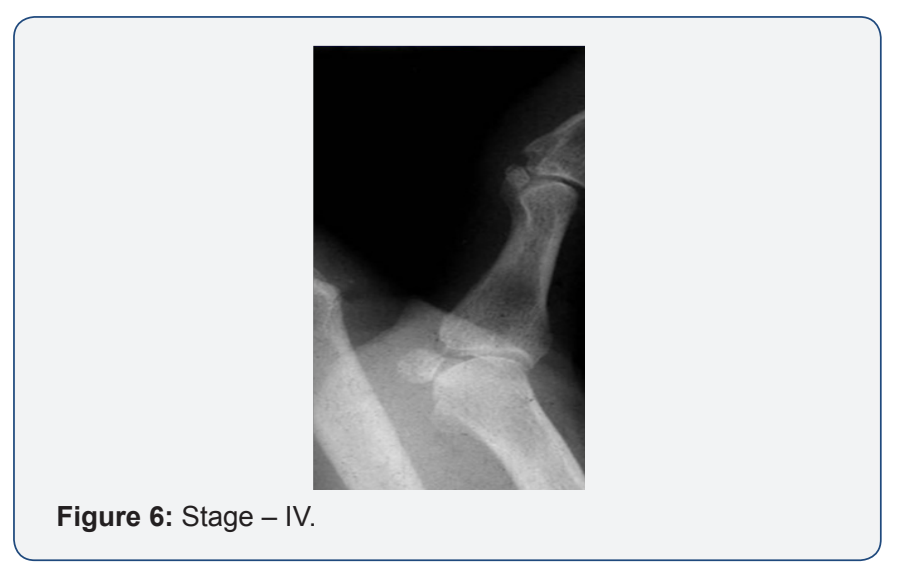

\section{Carpometacarpal Arthritis of the Thumb}
a. Age: 60 Years
b. Sex: Women(Post Menopausal)
c. Side: Right side; Both sides frequent
d. Predisposing Factors:
i. Trauma $(30 \%)$
ii. Developmental Anomalies
iii. Occupational
iv. Anatomical

\section{Symptoms}
a. Severe pain-Base of the thumb
b. Aggravated by movements
c. Swelling over the base of the thumb
d. Stiffness of the Thumb
e. Weak Grip

\section{(A)Conservative Treatment}
a. Physiotherapy
b. Radiotherapy
c. Splint
d. Intra-articular Steroids

\section{(B)Surgical Treatment}
a. Forage
b. Intra-articular Tenodesis
c. Excision of the Trapezium
d. Arthrodesis
e. Silicone rubber interpositional arthroplasty
f. Prosthetic Replacement
i. Charcot and Leri(1926)
ii. $\operatorname{Robert}(1936)$
iii. Forestier(1937)
iv. Lasserre,Pauzat and Derennes(1949)
v. Muller (1949) and Brittain (1952) - Arthrodesis of the carpometacarpal joint of the thumb. Stressed the difficulty of obtaining a successful fusion of this small joint.
vi. $\quad$ Dickson (1976):
a. Silicone rubber sponge interposition arthroplasty. 
b. Excellent results in 15 of the 16 wrists.

c. Silicone promotes development of repair fibrous tissue. vii. Swanson (1972) - Heat molded, intramedullary stemmed silicone rubber implant. Early results not encouraging due to advancement of insertion of abductor pollicis longus with reinforcement of capsule with a slip from flexor carpi radialis.

viii. Gervis (1949) 18 wrists with 16 good results. (1973) 12 wrists followed up for 6 to 22 years.

ix. Goldner \& Clippinger (1955) Excison of the Trapezium piece-meal.

X. $\quad$ Murley (1960) 39 wrists with 36 good results. Marmor \& Peter (1969) 7 wrists with 5 good results.

xi. Sims \& Bentley (1970) 27 Trapeziectomies with excellent results in 15, Good in 6, Fair in 5 \& Poor in one. Incidence of $54 \%$ of patients with associated TrapezioScaphoid Arthritis.

xii. Gervis (1949) 18 wrists with 16 good results.

xiii. Gervis (1973) 12 wrists followed up for 6 to 22 years

xiv. Murley (1960) 39 wrists with 36 good results.

xv. Goldner and Clippinger (1955) Excision of the Trapezium piece-metal.

xvi. Marmor and Peter (1969) 7 wrists with 5 good results. xvii. Sims and Bentley (1970) 27 Trapeziectomies with excellent results in 15 , good in 6 , fair in 5 and poor in one. Incidence of $54 \%$ of patients with associated TrapezioScaphoid arthritis.

xviii. Iyer (1981) 26 wrists with 25 good results.

\section{Clinical Evaluation}
a) Name
b) Age
c) Sex
d) Dominant Hand
e) Occupation
f) Time off work: Pre-op, Post-op \& Total.
g) Return to original occupation.
h) History of Injury.
i) Duration of complaints pre-op.
j) Time since surgery.

\section{Associated Conditions}
a) Cervical Spondylosis.
b) Periarthritis Shoulders.
c) Stenosing Tenovaginitis.
d) Median nerve compression.
i. Surgical-Incision.
ii. $\quad$ Post operative management (Table 1) (Figures 7-17).

Table 1: Clinical Evaluation.

\begin{tabular}{|c|c|c|c|c|}
\hline & $\begin{array}{c}\text { Number of } \\
\text { patients }\end{array}$ & $\begin{array}{c}\text { Number of } \\
\text { operations }\end{array}$ & \multicolumn{2}{|c|}{ Age (Years) } \\
\hline & & & Average & Range \\
\hline Males & 9 & 13 & 67.66 & $56-79$ \\
\hline Females & 9 & 13 & 58.11 & $41-70$ \\
\hline
\end{tabular}
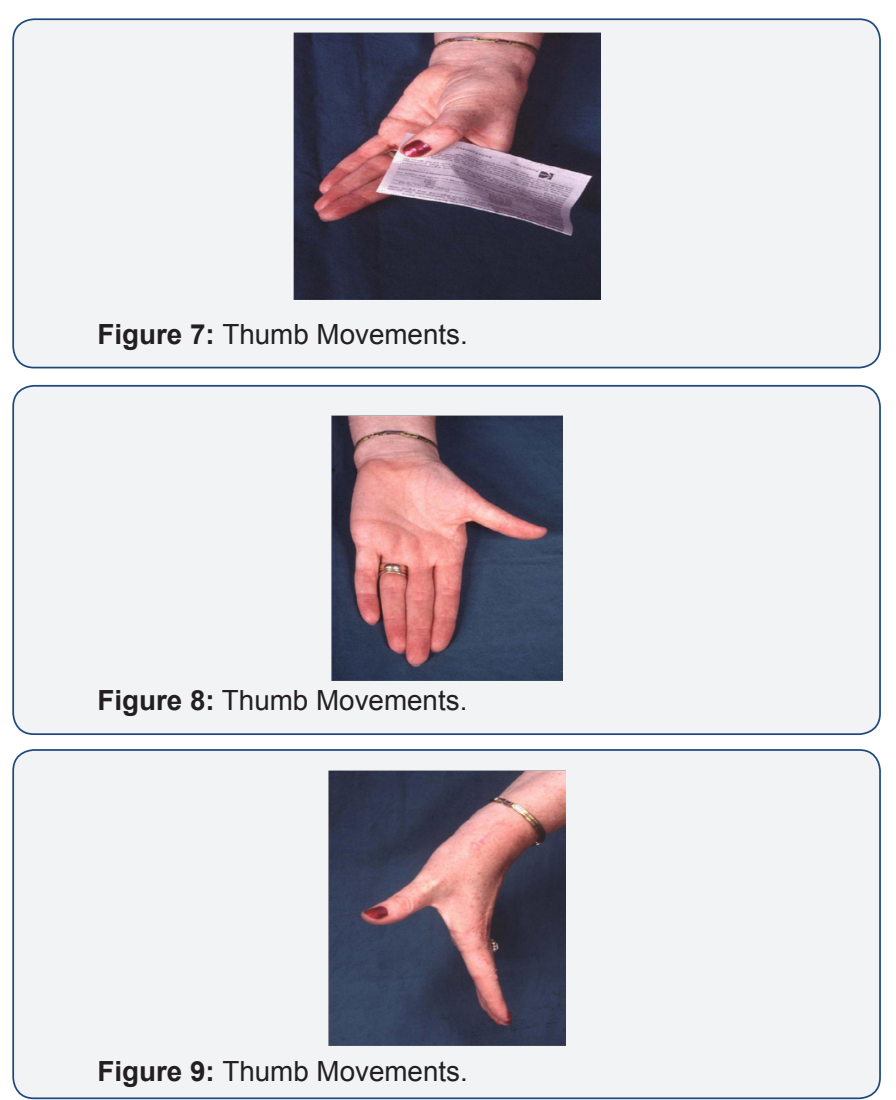

Figure 9: Thumb Movements.

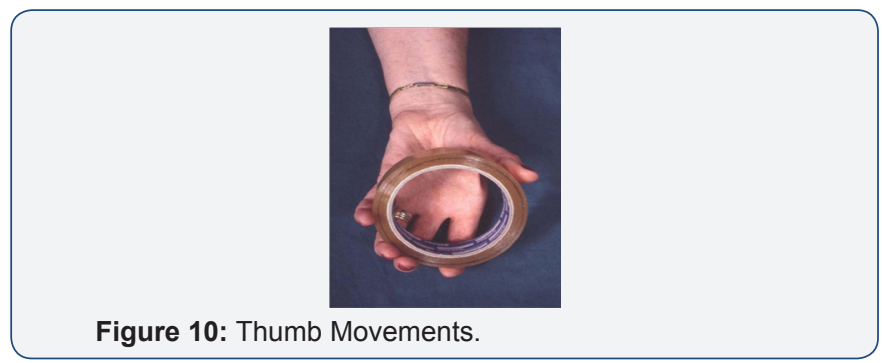



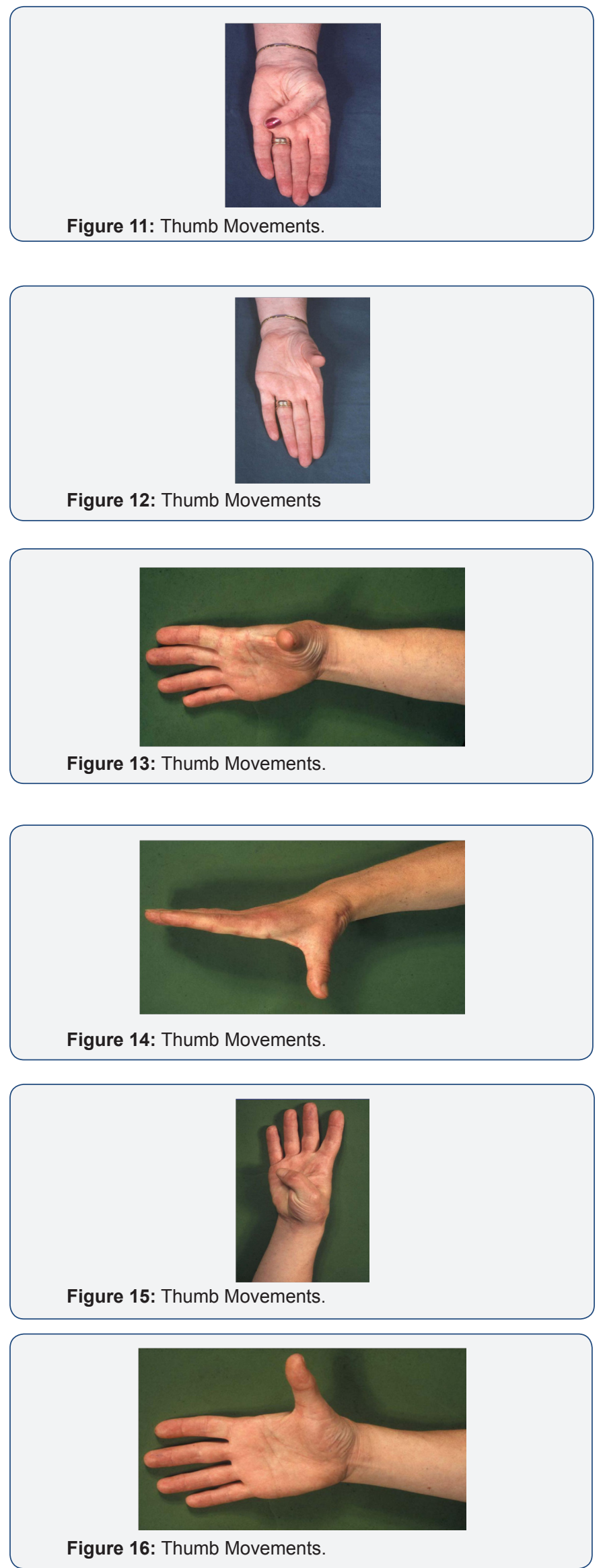

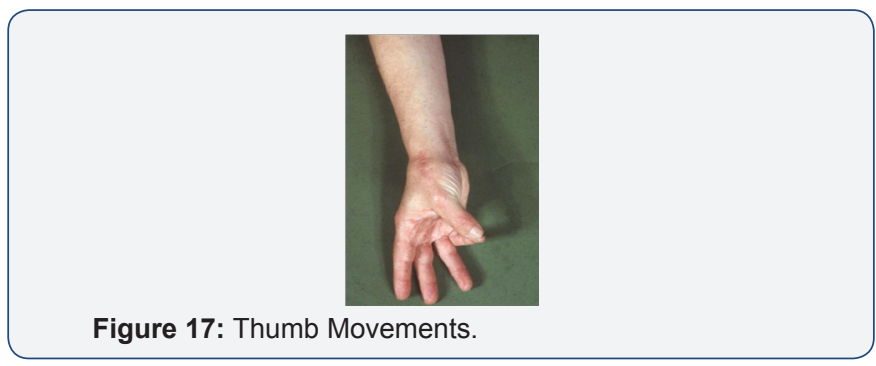

\section{Results}

\section{Thumb Movements:}

I. Abduction

a) Normal range + Power -18 wrists

b) Less than $50 \% \quad-8$ wrists

II. Opposition

a) Normal range + Power -14 wrists

b) N.range $+50 \%$ Power $\quad-9$ wrists

c) Less than $50 \% \mathrm{R}+\mathrm{P} \quad-3$ wrists

III. Adduction

a) Normal Power - 25 wrists

b) Poor - 1 wrist

IV. Circumduction

a) Normal -25 wrists

b) Poor - 1 wrist

\section{Associated Features:}

a) Cervical Spondylosis $-13 / 18$ patients.

b) Periarthritis Shoulders $-9 / 18$ patients.

c) Stenosing Tenovaginitis $-3 / 18$ patients.

d) Median nerve compression $-4 / 18$ patients (Surgical Decompression in 2 patients)

i. Follow up- 2 months to 14 years

ii. Duration of complaints pre-operative- 1 year to 10 years

iii. Total time off work- 3 months

iv. Return to original occupation- 11 patients

v. History of injury- $7 / 26$ wrists

vi. Dominant hand- $13 / 18$ patients

vii. Hand span

a) Bilateral cases (8 patients)- equal

b) $\operatorname{Rest}(10$ patients)- $1.25 \mathrm{cms}$ (average) 
viii. Shortening of the thumb

a) Bilateral cases (8 patients) - equal

b) Rest (10 patients) $-1 \mathrm{~cm}$ (average)

ix. Intermetacarpal angle

a) Normal $-23 / 26$ wrists

b) Less than normal $-3 / 26$ wrists

e) Functioning tendons of Flexor carpi radialis and Flexor pollicis longus $=26 / 26$ wrists.

f) Decreased sensations over the dorsum of the base of the thumb $=3 / 26$ wrists.

g) Keloid formation $=5 / 26$ wrists.

h) Palpable Neuroma $=$ None.

i) Opposition Grip:

a) Normal Power $=6$ wrists? ? ?Decreased power $=20$ wrists

j) Pinch Grip: (Figures 18-23).

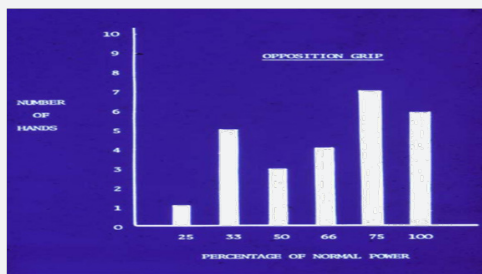

Figure 18: Graph of Opposition Grip.

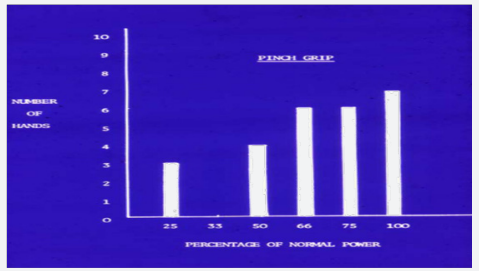

Figure 19: Graph of Pinch Grip.

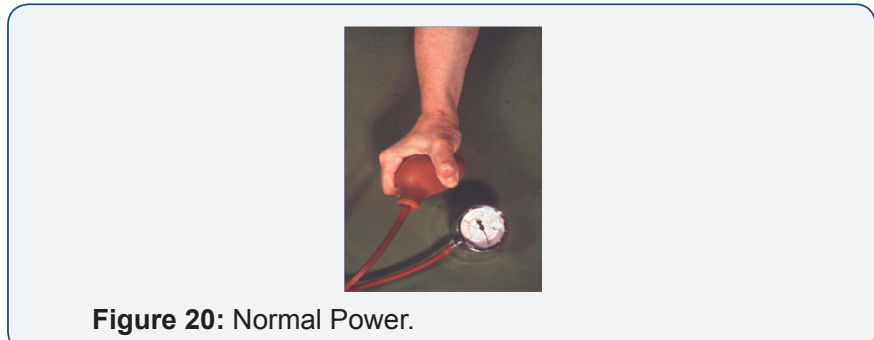

Figure 20: Normal Power

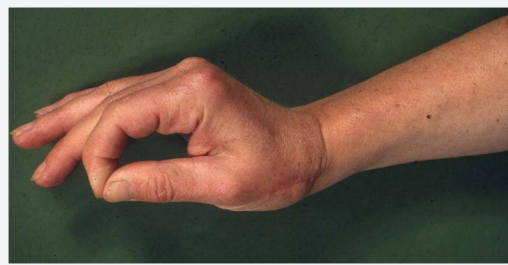

Figure 21: Pinch Grip
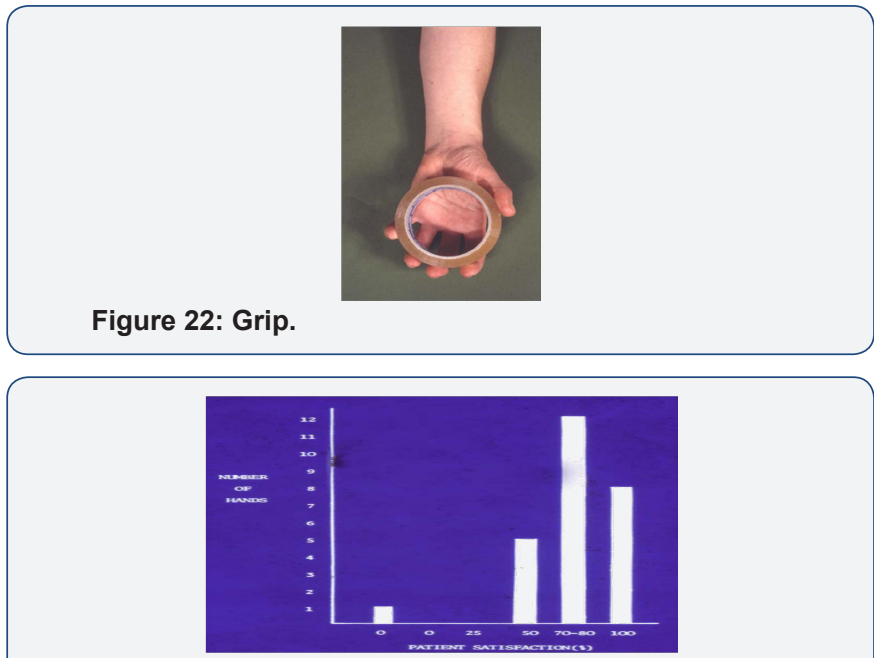

Figure 23: Graph of Patient Satisfaction vs number of hands

\section{Radiographic Assessment}

i. Level of first metacarpal base.

ii. Accessory Ossicles.

iii. Radiologic gap.

iv. Telescoping.

v. Stress views.

vi. Degenerative changes:

a) Base of first metacarpal

b) Distal Scaphoid

c) Elsewhere in the carpus

\section{Radiographic Features}
a) Telescoping $=14$ wrists (55\%)
b) Accessory Ossicles $=9$ wrists (40\%)
c) Radiological Gap $=1 \mathrm{~mm}$ to $6 \mathrm{~mm}$
d) Degenerative changes:
i. Base of first metacarpal $=14$ wrists
ii. Distal Scaphoid $=8$ wrists
iii. $\quad$ No changes $=11$ wrists (Figure 24).

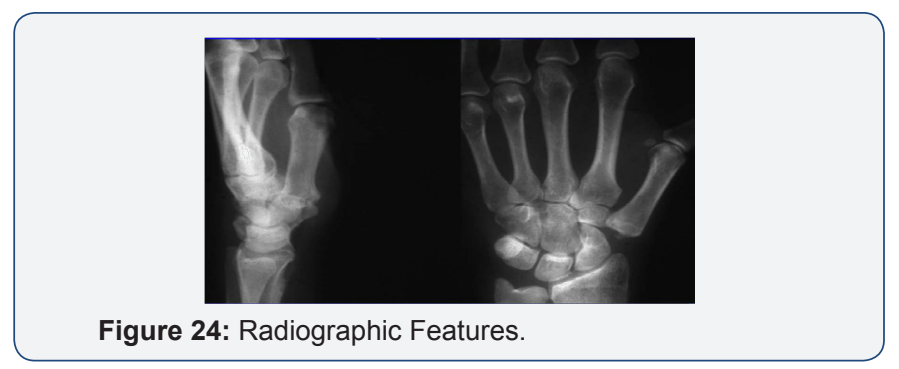

e) Residual Cartilage: 
i. $\quad$ Base of first MC -Nil in 3 wrists

ii. Present in 22 wrists Distal Scaphoid - Nil in 2 wrists

iii. Present in 23 wrists 6.Lateral subluxation of 1st MC on Abduction

iv. Marked subluxation in 3 wrists Moderate subluxation in 22 wrists (Figure 25).

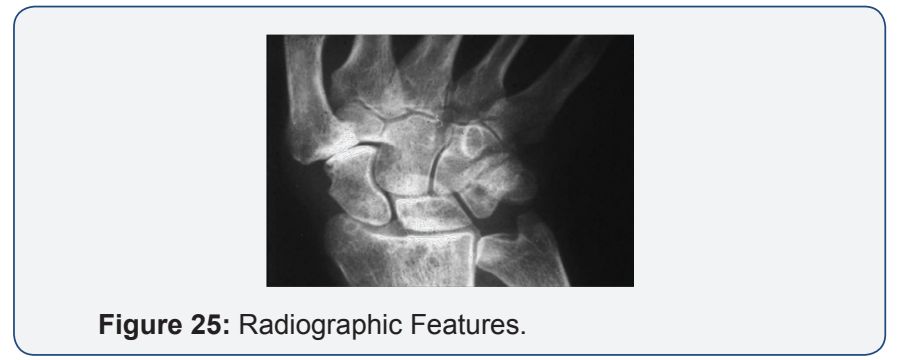

f) Maintenance of joint space despite subluxation of the 1st MC on the Scaphoid on radial deviation of the wrist.

g) Stress views of the wrist:

i. $\quad$ No changes $=9$ wrists

ii. Widening of the Sc-Trap.Jt $=12$ wrists

iii. Widening of the Sc-Cap.Jt $=6$ wrists

iv. Widening of gap between the bases of 1 st \& 2 nd MC's = 6 wrists (Figures 26-28).
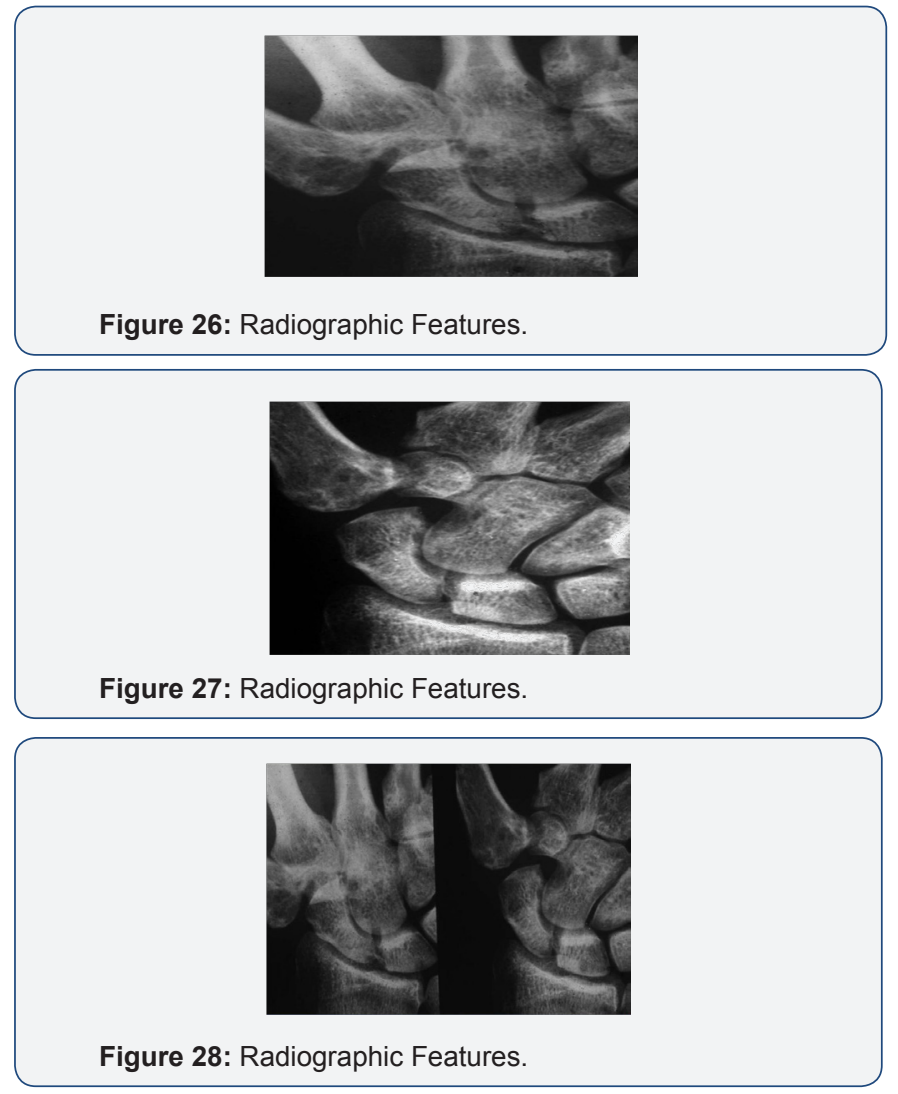

Arthrography of the Metacarpo-Scaphoid joint

Technique (Figures $29 \& 30$ )
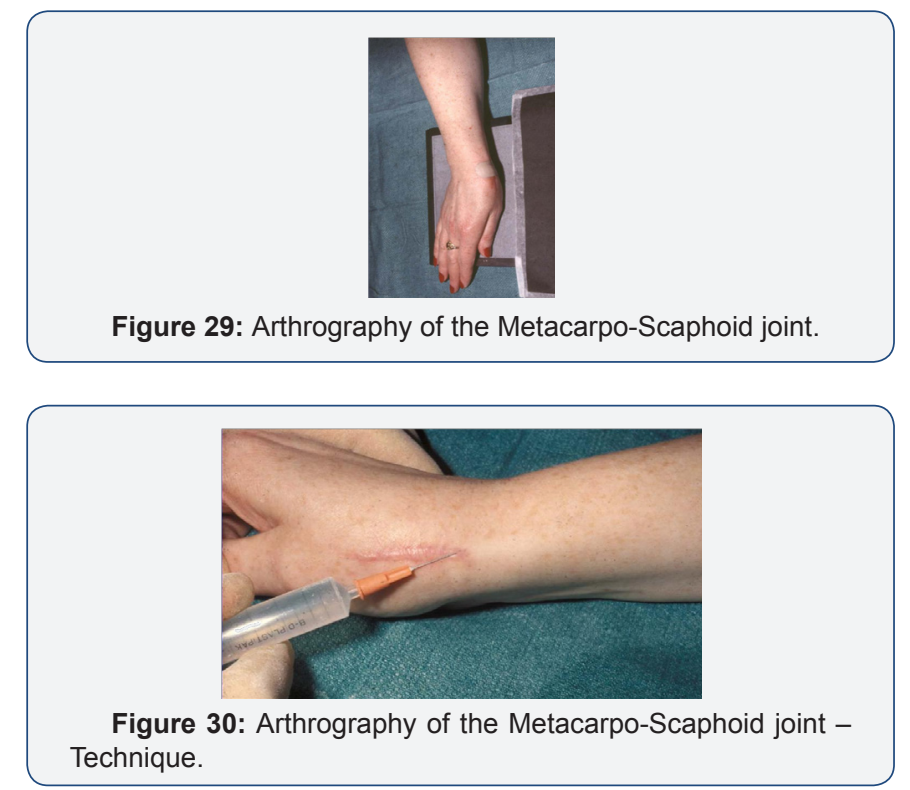

Arthrographic assessment
a) Amount of dye injected.
b) Ease of location of the joint \& injection.
c) Residual articular cartilage over:
i. Base of the first metacarpal.
ii. Distal Scaphoid.

\section{Arthrographic Assessment}
d) Joint Features?
(A) Isolated.
(B) Communications-
(C) Midcarpal
(D) Radiocarpal
(E) Radioulnar
(F) Tendon Sheaths
(G) Pouch between 1st \& 2nd metacarpal bases
e) Stress Views (Figures $31 \& 32$ ).

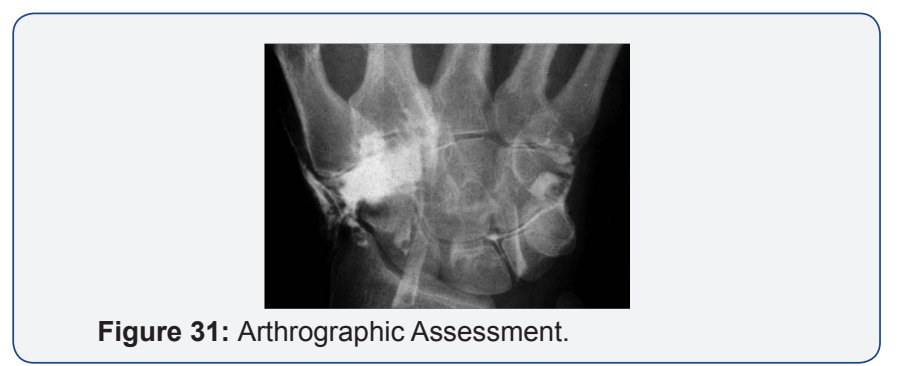




\section{Orthopedics and Rheumatology Open Access Journal}

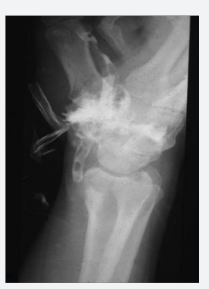

Figure 32: Arthrographic Assessment.

\section{Arthrographic Features}

a) Distinct Joint Space - 25 wrists

b) Comm. with midcarpal joint - 10 wrists

c) Comm. with radiocarpal joint - 2 wrists

d) Comm. with distal RU joint - 1 wrist

e) Comm. with tendon sheaths - 4 wrists

f) Contour-Irregular \& small - 16 wrists

i. $\quad$ Regular \& larger - 9 wrists (Figures 33-36).
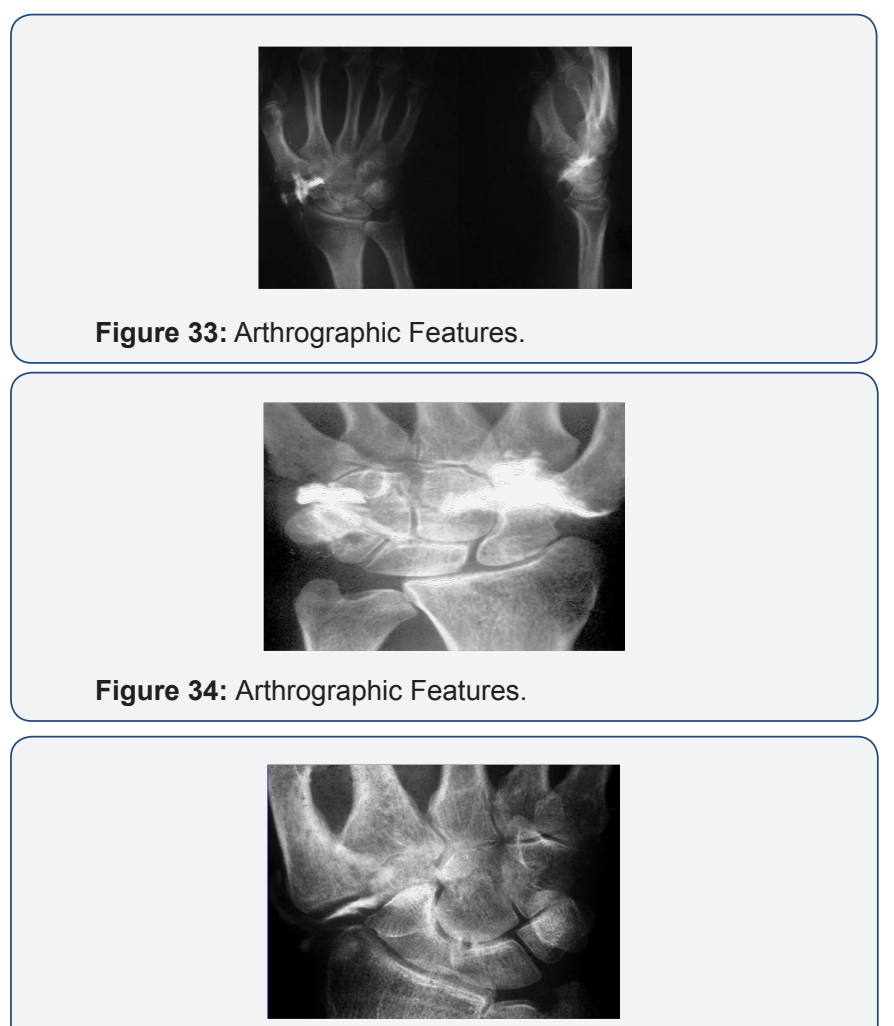

Figure 35: Arthrographic Features.

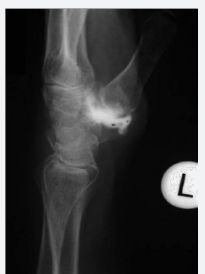

Figure 36: Arthrographic Features.

\section{Conclusion}

i. Excision of the Trapezium gives good results with respect to relief of pain.

ii. Good hand function despite some reduction in the power of Opposition grip and Pinch grip.

iii. Carpal Instability or Laxity may account for decreased Opposition grip \& Pinch grip.

iv. Distinct joint space

a) Small \& Irregular within 6 months of Surgery

b) Large \& Regular thereafter

c) Marked subluxation indicates weak grip

v. Late deterioration of pseudoarthrosis in one patient

\section{References}

1. Lasse Kvarnes and Olav Reikeras (1985) Osteoarthritis of the Carpometacarpal Joint of the Thumb. The Journal of Hand Surgery 10-B (1): 117-120.

2. Kvarnes L, Reikeras O (1985) Rheumatoid Arthritis at the Base of the Thumb treated by Trapezium Resection or Implant Arthroplasty. J Hand Surg Br 10-B (2): 195-196.

3. Paul C Dell, Ruth B Muniz (1987) Interposition Arthroplasty of the Trapeziometacarpal Joint for Osteoarthritis. Clinical Orthopaedics and Related Research 220: 27-34.

4. Helal B, McPherson I (1989) Replacement of the Trapezium with a Silicone Elastomer Universal Small Joint Spacer. J Hand Surg Br 14B (4): 456-459.

5. Conolly WB, Rath S (1993) Revision Procedures for complications of Surgery for Osteoarthritis of the Carpometacarpal Joint of the Thumb. J Hand Surg Br 18B (4): 533-539.

6. Varley GW, Calvey J, Hunter JB, Barton NJ, Davis TR (1994) Excision of the Trapezium for Osteoarthritis at the base of the Thumb. J Bone Joint Surg Br (Br) 76-B (6): 964-968.

7. Vandenbroucke J, De Schrijver F, De Smet L, Fabry G (1997) Simple Trapezectomy for Treatment of Trapeziometacarpal Osteoarthritis of the Thumb. Clin Rheumatol 16(3): 239-242.

8. Belcher HJ, Nicholl JE (2000) A Comparison of Trapeziectomy with and without ligament reconstruction and Tendon Interposition. J Hand Surg Br 25B (4): 350-356.

9. Downing ND, Davis TR (2001) Trapezial Space Height after Trapeziectomy: Mechanism of formation and benefits. J Hand Surg Br 26A (5): 862-868.

10. Horlock N, Belcher HJ (2002) Early versus late mobilization after simple excision of the Trapezium. J Bone Joint Surg Br 84-B (8): 11111115 .

11. Davis TR, Brady O, Dias JJ (2004) Excision of the Trapezium for Osteoarthritis of the Trapeziometacarpal Joint: A study of the benefit of ligament reconstruction or tendon Interposition. J Hand Surg Br 29A (6): 1069-1077.

12. Wheeless' Textbook of Orthopaedics > wheelessonline.com > Osteoarthritis > CMC Arthritis > Excision of the Trapezium.

13. Nilsson A, Liljensten E, Bergström C, Sollerman C (2005) Results from a degradable TMC joint Spacer (Artelon) compared with tendon arthroplasty. J Hand Surg Am 30(2): 380-389. 


\section{Orthopedics and Rheumatology Open Access Journal}

14. Nicole Murphy, Bhoomiah Dasari, Jo Adams (2009) A review of osteoarthritis of the trapeziometacarpal joint (TMJ). Journal of Rheumatology Occupational Therapy 24(1): 8-11.

15. Junior WG, Chaim RM, de Carvalho HB, Albertoni WM, Faloppa F (2011) Arthroplasty for trapezium excision and tendon interposition in rhizarthrosis cases: prospective study. Rev Bras Ortop 46(1): 75-82.

16. Nusem I, Goodwin DR (2003) Excision of the Trapezium and Interposition Arthroplasty with Gelfoam for the Treatment of Trapeziometacarpal Osteoarthritis. J Hand Surg Br 28B (3): 242-245.

17. Craig W Martin (2010) First carpo-metacarpal osteoarthritis and its association with occupation (with an emphasis on clerical workers) Work Safe BC Evidence- based practice group, PO Box 5350 Stn Terminal, Vancouver BC V6B 5L5.

18. CMC Joint Arthroplasty Utilizing the BioPro Modular Thumb Implant Louis S. Habryl, DO www.bioproimplants.com/downloads/dr_louis habryl_cmc_study.pdff.

19. Min J Park, Greg Lichtman, Jennifer B Christian, Jennifer Weintraub, James Chang, et al. (2008) Surgical Treatment of Thumb Carpometacarpal Joint Arthritis: A Single Institution Experience From 1995 to 2005. Hand 3(4): 304-310.

20. Pardini AG Jr, Freitas AD, Chaves AB, Freitas MB (2009) Comparative study between trapezium resection and tendon interposition with and without ligamentplasty in the management of carpometacarpal arthrosis of the thumb. J Hand Microsurg 1(1): 7-11.

21. Luc De Smet, Wouter Sioen (2007) Basal joint osteoarthritis of the thumb: trapeziectomy, with or without tendon interposition, or total joint arthroplasty? A prospective study. European Journal of Orthopaedic Surgery \& Traumatology 17(5): 431-436.

22. Nilsson A, Liljensten E, Bergström C, Sollerman C (2005) Results of a Degradable TMC joint spacer(Artelon) compared with tendon arthroplasty. J Hand Surg Am 30A (2): 380-389.

23. De Smet L, Sioen W, Spaepen D, van Ransbeeck H (2004) Treatment of Basal Joint Arthritis of the Thumb: Trapeziectomy with or without Tendon Interposition/Ligament Reconstruction. Hand Surg 9(5): 5-9.

24. Bo-Kun Kim, Hyun-Dae Shin, Kyung-Cheon Kim, Soo-Min Cha (2012) Hematoma Distraction Arthroplasty after Trapeziectomy in Advanced Osteoarthritis of the Trapeziometacarpal Joint. J Korean Orthop Assoc 47(1): 21-27.

25. Kuhns CA, Emerson ET, Meals RA (2003) Hematoma and distraction arthroplasty for thumb basal joint osteoarthritis: A prospective, singlesurgeon study including outcomes measures. J Hand Surg Am 28(3): 381-389.

26. Gray KV, Meals RA (2007) Hematoma and Distraction Arthroplasty for Thumb Basal Joint Osteoarthritis: Minimum 6.5-Year Follow-Up Evaluation. J Hand Surg Am 32(1): 23-29.

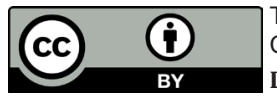

This work is licensed under Creative Commons Attribution 4.0 License DOI:10.19080/OROAJ.2016.03.555640
27. Bruce S Wolock, J Russell Moore, Andrew J Weiland (1989) Arthritis of the basal joint of the thumb. The Journal of Arthroplasty 4(1): 65-78.

28. Le Viet D, Kerboull L, Lantieri LA, Collins DE (1996) Stabilized resection arthroplasty by an anterior approach in trapeziometacarpal arthritis: Results and surgical technique. J Hand Surg Am 21(2): 194-201.

29. Illarramendi AA, Boretto JG, Gallucci GL, De Carli P (2006) Trapeziectomy and Intermetacarpal Ligament Reconstruction With the Extensor Carpi Radialis Longus for Osteoarthritis of the Trapeziometacarpal Joint: Surgical Technique and Long-Term Results. J Hand Surg Am 31(8): 1315-1321.

30. Ho PK, Jacobs JL, Clark GL (1985) Trapezium implant arthroplasty: Evaluation of a semiconstrained implant. J Hand Surg Am 10(5): 654660 .

31. Heyworth BE, Jobin CM, Monica JT, Crow SA, Lee JH, et al. (2009) LongTerm Follow-Up of Basal Joint Resection Arthroplasty of the Thumb with Transfer of the Abductor Pollicis Brevis Origin to the Flexor Carpi Radialis Tendon. J Hand Surg Am 34(6): 1021-1028.

32. O'Leary ST, Grobbelaar AO, Goldsmith N, Smith PJ, Harrison DH (2002) Silicone Arthroplasty for Trapeziometacarpal Arthritis. J Hand Surg Br 27B (5): 457-461.

33. Endress RD, Kakar S (2014) Double Tightrope for Basilar Thumb Arthritis. J Hand Surg Am 39(12): 2512-2516.

34. Jones DB Jr, Rhee PC, Shin AY, Kakar S (2013) Salvage Options for Flexor Carpi Radialis Tendon Disruption During Ligament Reconstruction and Tendon Interposition or Suspension Arthroplasty of the Trapeziometacarpal Joint. J Hand Surg Am 38(9): 1806-1811.

35. (1989) Arthritis of the basal joint of the thumb. From Department of Orthopaedic Surgery, the Johns Hopkins University School of Medicine, Baltimore, Maryland. The Journal of arthroplasty 4(1): 65-78.

36. Aliu O, Davis MM, DeMonner S, Chung KC (2013) The Influence of Evidence in the Surgical Treatment of Thumb Basilar Joint Arthritis. Plast Reconstr Surg 131(4): 816-828.

37. Thumb Basilar Joint Arthritis.

38. Le Viet D, Kerboull L, Lantieri LA, Collins DE (1996) Stabilized resection arthroplasty by an anterior approach in trapeziometacarpal arthritis: Results and surgical technique. J Hand Surg Am 21(2): 194-201.

39. Page No.52,Thesis submitted for the PhD on 29th January 2014,to the University of Erasmus MC, Netherlands on 'Thumbs Up' Surgical Management and outcome of Primary Osteoarthritis at the base of the Thumb by Guus M.Vermeulem

\begin{tabular}{l} 
Your next submission with Juniper Publishers \\
will reach you the below assets \\
- Quality Editorial service \\
- Swift Peer Review \\
- Reprints availability \\
- E-prints Service \\
- Manuscript Podcast for convenient understanding \\
- Global attainment for your research \\
- Manuscript accessibility in different formats \\
( Pdf, E-pub, Full Text, Audio) \\
- Unceasing customer service \\
Track the below URL for one-step submission \\
https://juniperpublishers.com/online-submission.php \\
\hline
\end{tabular}

